\title{
Influence of Culture on Contraceptive Utilization Among HIV-Positive Women in Brazil, Kenya, and South Africa
}

\author{
Catherine S. Todd • Mark A. Stibich - Fatima Laher • \\ Monica S. Malta - Francisco I. Bastos - Kennedy Imbuki • \\ Douglas N. Shaffer · Samuel K. Sinei · Glenda E. Gray
}

Published online: 26 November 2010

(C) Springer Science+Business Media, LLC 2010

\begin{abstract}
Contraceptive choice and discontinuation are poorly understood among HIV-positive women, and HIV disease and culture may influence decisions. We assessed factors influencing contraceptive decision-making among HIV-positive women in three countries. This qualitative assessment of 108 HIV-positive women (36/site, selected by age and parity strata) was conducted in Rio de Janeiro, Brazil; Kericho, Kenya; and Soweto, South Africa. Freelist interviews assessed knowledge and attitudes towards contraception and were analyzed enumerating frequency and saliency of mentions. There was intersite consensus around list items but priority and themes varied. Site-specific factors influencing contraceptive choice were male partner wishes and fertility desire (Brazil), side-effects (South Africa), and impact on health and HIV progression (Kenya). Age, parity, and taking antiretroviral therapy
\end{abstract}

C. S. Todd $(\bowtie)$

Department of Obstetrics and Gynecology, Columbia University, 622 West 168th Street, New York, NY 10032, USA

e-mail: cst2121@columbia.edu

M. A. Stibich

Lacuna Projects, Houston, TX, USA

F. Laher - G. E. Gray

Perinatal HIV Research Unit, University of Witwatersrand,

Soweto, South Africa

M. S. Malta · F. I. Bastos

Oswaldo Cruz Foundation, Rio de Janeiro, Brazil

F. I. Bastos

CAPES/Fulbright Visiting Scholar Program, Brown University,

Providence, RI, USA

K. Imbuki $\cdot$ D. N. Shaffer $\cdot$ S. K. Sinei

Walter Reed Project, Kericho, Kenya
(ART) impacted some themes. Contraceptive use among HIV-positive women is substantially influenced by culture and other factors. Counseling efforts should consider individual factors in method selection and offer method variety to accommodate changing needs.

Keywords HIV - Fertility desire - Contraception . Menstruation · Future fertility $\cdot$ Condom use

\section{Introduction}

An estimated 33 million people are infected with HIV globally, and approximately half are women [1]. Female HIV acquisition often occurs early within the reproductive period, thus, is a factor in fertility decision-making [1]. This matter is increasingly important due to extended lifespan resulting from antiretroviral therapy (ART), including those infected at birth now entering adulthood [2]. The need for effective, acceptable contraception for HIV-positive women has been identified [3-5], as have approaches to reducing barriers to contraceptive initiation and continuation $[6,7]$.

Contraceptive method variety, price, and availability vary by country [8]. Method choice and continuation are further impacted by individual factors changing over time and by tolerance of perceived or actual side-effects [9-11]. Cultural norms also may effect method selection or continuation [1214]. HIV and ART influence contraceptive use, though may not be the most important factors $[15,16]$. Thus, contraceptive initiation and continuation are influenced by the interplay of policy, culture, and demographic factors; HIV status adds another dimension to these decisions.

Fertility intentions are similarly multifactorial. Most studies indicate that HIV diagnosis reduces desired fertility 
[15, 17-19]. However, a comparison of HIV-positive to negative women in Malawi noted that, while desired fertility was lower for HIV-positive women, the pregnancy rate was the same between groups [20]. High rates of unintended pregnancy have been reported among HIVpositive women participating in studies in South Africa [21]. Thus, while HIV and ART effect stated fertility intentions, actual contraceptive use may not be impacted in the same direction [22]. Further, stated desire for no further pregnancies does not necessarily indicate contraceptive continuation or correct use [20-22].

The impact of HIV and ART on contraceptive use varies between settings [15, 16]. Increased contraceptive uptake has been reported in response to HIV diagnosis or ART initiation [18, 19, 23]. However, the effect of HIV on contraceptive use is not uniform between settings, where HIV-positive women may be less or equally as likely to use contraception as uninfected women [20, 24]. In Zambia, contraceptive discontinuation rates among HIV-positive women were high regardless of assigned method or educational intervention $[25,26]$; desired fertility was a rarely stated reason for discontinuation. Given this data, a qualitative assessment for context of contraceptive method choice, discontinuation, and relative effect of HIV on these choices is indicated.

Qualitative studies produce rich contextual data but are time-consuming and have limited utility when comparing between sites. Freelist (FL) methodology was developed as a hybrid technique to sample terms contained within a given category (e.g., cultural domain), without imposing investigator assumptions on respondents [27, 28]. This methodology allows qualitative data collection while permitting rapid, quantitative analysis and has been used to assess various aspects of HIV in diverse cultural settings $[29,30]$. Further, the quantitative nature of the FL allows for data to be compared across sites to gain insight on the cultural variability present.

Nascent efforts are underway to better integrate contraceptive provision with HIV services [6, 7]. The purpose of this multisite study is to describe the relative importance of HIV infection and culture regarding contraceptive choice, utilization, and discontinuation among HIV-positive women in Rio de Janeiro, Brazil; Kericho, Kenya; and Soweto, South Africa. The results may guide both culturally informed counseling efforts and contraceptive method selection better tailored to the needs of HIV-positive women and thus improve current and future programming efforts.

\section{Methods}

This qualitative assessment was inspired by information presented at the 16th International AIDS Conference, which acknowledged unplanned pregnancy as a burgeoning issue for HIV-positive women with the expansion of ART [7]. The sites were selected based on duration of ART availability, with Brazil having ART widely available for more than 10 years, Kenya having an expanding program with ART widely available for about 3 years, and South Africa with ART newly available in the public sector at the time of protocol development.

\section{Brazil Setting}

Rio de Janeiro, in southeastern Brazil, has a metropolitan population of approximately 10 million. Antenatal HIV prevalence for this area was $0.537 \%$ in 2004 [31]. ART has been available in Brazil since 1991 with universal access to free ART mandated by law and fully implemented since 1996; the coverage rate for eligible female patients was $95.3 \%$ in 2007 [32, 33]. The national contraceptive prevalence rate (CPR) in 2006 was $81 \%$; reversible methods and sterilization are publicly funded and pregnancy termination is highly restricted [34]. A recent attempt made by the Special Secretary on Human Rights to decriminalize abortion was strongly rejected by different social actors, particularly religious leaders and politicians from different affiliations. Recent studies conducted in Brazil with HIVpositive women identified prominent desire for future fertility, and, despite government provision of methods, lack of proper access to reproductive health care and subsequent use of less effective contraceptive methods (e.g. withdrawal). Participants also reported a lack of reproductive health counseling and lack of contraceptive provision during their monthly appointments [35-38].

The viewpoint of Brazilian women collectively regarding childbearing has changed dramatically in the last decades, reflected by a decline in total fertility rate (TFR) from 2.5 in 1996 to 1.8 lifetime pregnancies/woman in 2006 [39]. Reasons associated with these changes, which apply to women from all social strata, are progressive urbanization (more than $81 \%$ of the population lived in urban areas in 2006) and the gradual replacement of traditional values by a Western style of living, characterized by both small families and an increasing proportion of uniparental families (i.e. households composed by women and their children, with no cohabiting male partner). Such changes are in conflict with traditional values where a large number of children are deemed ideal. However, Brazilian women still highly value the point of view of their husbands/male partners when weighing fertility decisions, in the context of a society where deep social and gender inequality still prevails. Currently, women do want to have children, but fewer children than were considered the norm in previous decades. Further, childbearing is seen as a self-fulfillment option rather than a means of securing stable marital or 
other unions. Approximately $40 \%$ of women support their children on their own, without any help from male partners, especially in the most deprived areas like the favelas [40]. This trend speaks to an increasing number of divorces and separations, economic-driven migration, and the tremendous impact of violent deaths on male mortality in Brazil [41].

Participants for this study were recruited from one health center affiliated with the Municipal Health Secretariat and one charity sponsored by the Catholic Church, dedicated to the assistance of disenfranchised communities, including people living in slums and in the streets. Most patients attending these two service sites belong to lower social strata and to the low-middle class, have low educational levels, and have been clinically ill for a long time.

\section{Kenya Setting}

Kericho District, in Western Kenya's Rift Valley Province, has a population of approximately 469,000 , with the economy supported largely by commercial farms. HIV prevalence among adult women ranges from 17.4 to $19.1 \%$ $[42,43]$. ART has been available since 2004, with estimated coverage of $40.5 \%$ of those eligible $(\mathrm{CD} 4<250)$ in 2007 [44]. Kenya has experienced a plateau in fertility rates over the last decade [45]. In Rift Valley Province, the CPR in 2003 was 34\%; modern methods are available at no cost through the government health system and pregnancy termination is legal under extremely limited circumstances [45]. Kenya experienced a steady decrease in TFR between 1960 and 1995 but since that time, a plateau has been reached with a TFR of 4.6 in 2009 [46]. Birth rates have been noted to be increasing in some areas of the country and in some populations, attributed to decreased funding for family planning and lack of support for modern contraceptive methods by some religious and ethnic groups [47, 48]. Childbearing is extremely important to solidify a marriage as men may take several wives, and influence among wives is mediated by number of children, specifically sons. Thus, infertility may lead to marital disharmony or be used as a reason to take a second wife; childless older women are often objects of pity [49]. In some communities in the Kericho area, women who are not able to give birth are considered to be utilizing resources without being able to give back to the society in terms of the number of children. Some men may discontinue sexual relations with unproductive wives because they are considered to be "cold" or fruitless.

The Walter Reed Project (WRP), in collaboration with the Kenyan Ministry of Health, has provided ART through PEPFAR since 2004. Participants were enrolled from clinics at the Kericho District Hospital, which provides clinical care for HIV-positive individuals and works in conjunction with the Walter Reed Project on a variety of clinical trials. Kericho District Hospital is the largest public care facility in the Western Rift Valley region and serves a catchment area population of 2.5 million people, with 40,000 people currently enrolled in HIV care and 18,000 receiving ART.

\section{South Africa Setting}

Soweto, housing $65 \%$ of Johannesburg's metropolitan population, is a peri-urban area with antenatal HIV prevalence of $29.7 \%$ (95\% CI 29.1-32.8) [50]. Public sector ART was initiated in 2004, with $16.3 \%$ coverage nationally by 2006 [51]. The national health system provides hormonal contraceptives, male condoms, intrauterine devices (IUDs), and elective first trimester pregnancy termination at no cost to South African residents. In Gauteng Province, where Soweto is located, the CPR was $63.1 \%$ in 2003; however, only $26.3 \%$ of reproductive-aged women consistently used contraception over a 1 year period in 2006 [52]. Elective first-trimester termination of pregnancy was legalized in South Africa in 1996. In 2001, 13.6\% of pregnancies in Soweto were terminated [53]. HIV-positive Sowetan women receiving ART seem to access this service with greater frequency: a quarter of those who became pregnant elected to terminate [54]. Though contraception is widely available, coital debut and childbearing occur early in a woman's reproductive years. Establishing fertility, often several times, has traditionally been a pre-condition of marriage as a man is unwilling to pay a bride price (lobola) unless there is some guarantee that children will result from the union [55]. However, impact of the high national HIV prevalence in at least one South African province (KwaZulu Natal) has altered this practice such that virginity is prized over fertility demonstration for marriage [56]. Despite this change, being considered a woman in South African society continues to be linked to having a child. Potentially for this reason, among HIVpositive women, younger women and those who have lost a child are more inclined to aspire toward childbearing [57].

The Perinatal HIV Research Unit (PHRU) is situated at the Chris Hani Baragwanath Hospital, a referral and clinical trials site in Soweto. At the time of the study, an estimated 1,800 HIV-positive women were receiving services at PHRU. A survey of 563 HIV-positive women attending PHRU revealed that $49 \%$ had finished high school, $61 \%$ were unemployed, $8 \%$ were married, and $78 \%$ were in a sexual relationship [58].

Eligibility

Eligible participants were HIV-positive women aged 15-40 (South Africa), 18-40 (Brazil), or 18-45 (Kenya) years, 
with access to regular medical care, and able to provide informed consent. Participants were purposively selected based on age $(<23,23-30,>30$ years $)$ and parity $(0,1-2$, $>2$ ) strata creating nine possible groups, in an effort to interview women of various ages and characterized by a range of childbearing experiences within each cultural setting. A convenience sample was recruited consisting of four women/group/site. Approvals were received from the institutional review boards of National School of Public Health (CEP/ENSP) in Brazil, the Kenya Medical Research Institute (KEMRI) and Walter Reed Army Institute of Research (WRAIR) for Kenya, Witwatersrand University in South Africa, and the University of California, San Diego and Columbia University.

\section{Freelist Interviews (FLIs)}

The FL technique was familiar to investigators at each site, who oversaw training and implementation at their respective sites with input from the U.S.-based investigators. Both an FL overview and guide were developed for use by U.S.-based investigators for training. Training activities included pilot-testing of six pre-determined FL statements at each site. Additional site-specific FL statements were developed through an iterative process that began with the local study staff team developing statements that met study objectives while conforming to local understanding of the cultural domain. These statements were based on focus group discussions (FGDs) and in-depth interviews (IDIs) previously conducted at each site. Once constructed, statements were then pilot-tested to assure face and content validity. This process was repeated at each site, with each site adding 1-2 site-specific questions of interest to the local research team. Each participant was asked multiple FL questions in same order as previous research by members of the study team demonstrated little fatigue or interaction among FLs [59].

In response to each statement, participants created a list of items contained within a category; in general, 30 participants will fully elucidate a cultural domain [60]. FLIs were conducted individually with responses transcribed by the interviewing staff member. The FLI instrument was identical for all sites for the first six statements, (Fig. 1) with one to three additional site-specific statements. The FL guide contained specific instructions with regard to how participants should be guided to construct a list with unrelated examples (e.g. "List all of the foods people eat for breakfast") provided to prevent leading by the interviewer. Probing was also addressed, with specific instructions that new or unusual list items should always be probed and that list items involving quantities or qualifications should also be probed. After lists were completed, staff periodically probed responses, particularly unusual

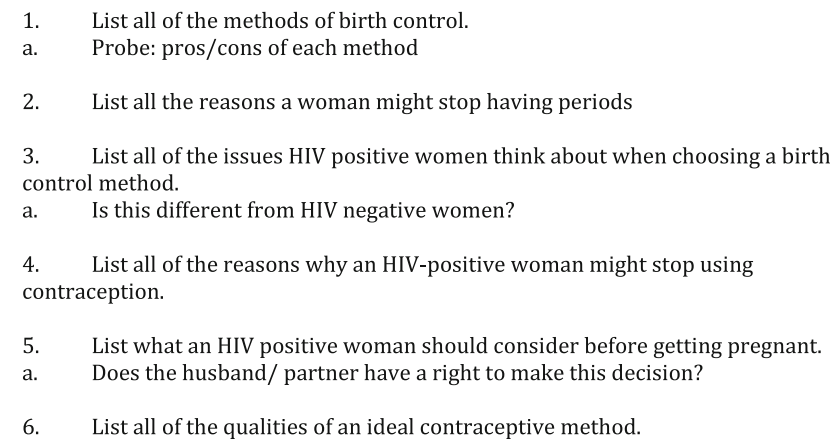

Fig. 1 Freelist statements common to all sites and site-specific statements

ones, for more contextual information. Pile sorting, a method sometimes used to follow up on FL data, was not done because average list length was insufficient to yield adequate variation [61].

\section{Data Collection}

Potential participants were identified during clinic visits, screened for inclusion criteria, and taken to a private room for study information and informed consent. Participants completed a standardized screener about HIV, ART, obstetric history, and contraceptive utilization and then completed the FL exercise administered by trained female study staff. Participants received a standard compensation of $\$ 10$ at each site for time and travel. Operationally, the FLIs followed FGD and IDI phases of the study at each site. Where possible, the same trained female staff conducted interviews for all phases. There was no specific order of sites for study activity performance and the protocol was developed with the assumption that sites would have activities in process simultaneously. The protocol also specified that participants from the FGD or IDI phases were not eligible for participation in the FLIs.

\section{Data Analysis}

Descriptive statistics were generated for demographic and reproductive health characteristics. Primary FL analysis was conducted in two phases [27]. The first phase was language standardization across lists. FLs were then analyzed using ANTHROPAC version 4.98 to examine the frequencies and saliency of each item [62]. Saliency was measured using Smith's $S$ (a frequency count weighted inversely by an item's rank in each list), reported with the frequency in the Results section [63]. Age, parity, and ART status were compared to demographic variables, contraceptive method, and select FL mentions with $\chi^{2}$ testing to gain additional insight on how these three variables may relate to contraceptive and fertility decision making. 


\section{Results}

Demographics

A total of 108 women (36/site) participated; demographic and reproductive health characteristics are summarized in Table 1. Condoms were the most popular contraceptive method used by participants at each site at the time of interview. Condom use did not vary substantially by age; $19(47.5 \%)$ reporting using condoms alone or combined with another method among the oldest age group (>30 years), compared to $20(55.6 \%)$ and $16(50.5 \%)$ for the middle (23-30 years) and younger age ( $<23$ years) groups $\left(c^{2}(2, N=108)=0.51, p=0.776\right)$. Parity also did not impact reported condom use. Among other methods, notable trends were that prior tubal ligation was only reported by women with at least three prior pregnancies and was more likely among women aged 31 years or more. Hormonal contraceptive use (e.g. injectables, pills, and implants) increased with parity but not with age. ART status varied significantly by age with $8(25.0 \%)$ of the youngest group reporting ART use compared to 19 (55.9\%) and $27(77.1 \%)$ for the middle and oldest groups, respectively $\left(c^{2}(2, N=101)=18.39, p<0.001\right)$.

\section{Factors Relating to Method Characteristics}

The lists for contraceptive methods and their advantages/ disadvantages are summarized in Table 2; lists were consistent across sites. For condoms, advantages included protection against sexually transmitted infections (STIs) and no side effects while disadvantages included need for partner participation and possibility of breakage/bursting. For injectable contraceptives, advantages included duration and amenorrhea (for some respondents) while disadvantages included side effects (particularly weight changes) and amenorrhea/dysfunctional bleeding. The pill had the advantage of oral administration and disadvantages of being easily forgotten, causing side effects, perceived interference with ART, and not preventing STIs. Generally, IUDs were associated only with disadvantages, such as being a foreign object or increasing infection risk (heightened by HIV status).

Table 1 Demographic and reproductive health characteristics of HIV-positive women completing Freelist interviews in Rio de Janeiro, Brazil; Kericho, Kenya; and Soweto, South Africa $(N=108)$

\begin{tabular}{|c|c|c|c|c|c|c|c|c|c|}
\hline \multirow[t]{2}{*}{ Characteristic } & \multirow[t]{2}{*}{ Total } & \multirow[t]{2}{*}{ Mean } & \multicolumn{2}{|c|}{ Brazil $(N=36)$} & \multicolumn{2}{|c|}{ Kenya $(N=36)$} & \multicolumn{2}{|c|}{ South Africa $(N=36)$} & \multirow[t]{2}{*}{$p$-value } \\
\hline & & & Site total & Site mean & Site total & Site mean & Site total & Site mean & \\
\hline \multirow[t]{2}{*}{ Age (mean) } & & 28.2 & & 27.8 & & 29.4 & & 27.5 & 0.89 \\
\hline & $N$ & Avg. & $N$ & Avg. & $N$ & Avg. & $N$ & Avg. & \\
\hline Pregnancies & 235.0 & 2.2 & 54.0 & 1.5 & 96.0 & 2.7 & 85.0 & 2.4 & 0.034 \\
\hline Live births & 187.0 & 1.7 & 34.0 & 0.9 & 75.0 & 2.1 & 78.0 & 2.2 & $<0.001$ \\
\hline Miscarriages & 18.0 & 0.2 & 2.0 & 0.1 & 10.0 & 0.3 & 6.0 & 0.2 & 0.350 \\
\hline \multirow[t]{2}{*}{ Abortions } & 19.0 & 0.2 & 12.0 & 0.3 & 5.0 & 0.1 & 2.0 & 0.1 & 0.168 \\
\hline & $N$ & $\%$ & $N$ & $\%$ & $N$ & $\%$ & $N$ & $\%$ & \\
\hline Married & 35.0 & 32.4 & 8.0 & 22.2 & 23.0 & 63.9 & 4.0 & 11.1 & $<0.01$ \\
\hline On ART & 54.0 & 50.0 & 17.0 & 47.2 & 21.0 & 58.3 & 16.0 & 44.4 & 0.241 \\
\hline $\begin{array}{l}\text { Contraceptive } \\
\text { method }\end{array}$ & $N$ & $\%$ & $N$ & $\%$ & $N$ & $\%$ & $N$ & $\%$ & \\
\hline Condoms & 55.0 & 50.9 & 25.0 & 69.4 & 15.0 & 41.7 & 15.0 & 41.7 & 0.025 \\
\hline Pill & 16.0 & 14.8 & 10.0 & 27.8 & 5.0 & 13.9 & 1.0 & 2.8 & 0.011 \\
\hline DMPA & 16.0 & 14.8 & 1.0 & 2.8 & 6.0 & 16.7 & 9.0 & 25.0 & 0.027 \\
\hline Abstinence & 8.0 & 7.4 & 1.0 & 2.8 & 6.0 & 16.7 & 1.0 & 2.8 & 0.034 \\
\hline Tubal sterilization & 8.0 & 7.4 & 4.0 & 11.1 & 2.0 & 5.6 & 2.0 & 5.6 & 0.583 \\
\hline None & 6.0 & 5.6 & 1.0 & 2.8 & 2.0 & 5.6 & 3.0 & 8.3 & 0.589 \\
\hline Nuristerate & 5.0 & 4.6 & $\mathrm{n} / \mathrm{a}$ & $\mathrm{n} / \mathrm{a}$ & $\mathrm{n} / \mathrm{a}$ & $\mathrm{n} / \mathrm{a}$ & 5.0 & 13.9 & 0.005 \\
\hline Other $^{\mathrm{b}}$ & 10.0 & 9.3 & 4.0 & 11.1 & 3.0 & 8.3 & 3.0 & 8.3 & 0.858 \\
\hline $\begin{array}{l}\text { Dual method (male } \\
\text { condom }+ \text { other } \\
\text { method) }\end{array}$ & 19.0 & 17.6 & 10 & 27.8 & 6 & 16.7 & 3 & 8.3 & 0.025 \\
\hline
\end{tabular}

$N$ number, DMPA depot medroxyprogesterone acetate, avg. average 
Table 2 Stated contraceptive methods known by HIV-positive women in Rio de Janeiro, Brazil; Kericho, Kenya; and Soweto, South Africa $(N=108$, average list length $=4.25$, total items listed $=459)$

\begin{tabular}{|c|c|c|c|c|c|c|c|c|c|}
\hline \multirow[t]{3}{*}{ Item } & \multicolumn{3}{|c|}{ Brazil } & \multicolumn{3}{|c|}{ Kenya } & \multicolumn{3}{|c|}{ South Africa } \\
\hline & \multicolumn{3}{|c|}{$(N=36$, avg. length $=4.03)$} & \multicolumn{3}{|c|}{$(N=36$, avg. length $=4.50)$} & \multicolumn{3}{|c|}{$(N=36$, avg. length $=4.22)$} \\
\hline & Freq. & $\%$ & Smith's $S$ & Freq. & $\%$ & Smith's $S$ & Freq. & $\%$ & Smith's $S$ \\
\hline Male condom & 36 & 100.0 & 0.8 & 34 & 94.4 & 0.5 & 34 & 94.4 & 0.7 \\
\hline Pill & 36 & 100.0 & 0.9 & 33 & 91.7 & 0.7 & 33 & 91.7 & 0.6 \\
\hline Sterilization & 25 & 69.4 & 0.2 & 10 & 27.8 & 0.1 & 17 & 47.2 & 0.2 \\
\hline Injectable/Insertable ${ }^{a}$ & 17 & 47.2 & 0.3 & 35 & 97.2 & 0.7 & 35 & 97.2 & 0.8 \\
\hline Loop/IUD & 15 & 41.7 & 0.1 & 24 & 66.7 & 0.2 & 17 & 47.2 & 0.1 \\
\hline Female condom & 8 & 22.2 & 0.1 & 8 & 22.2 & 0.1 & 14 & 38.9 & 0.1 \\
\hline Vasectomy & 2 & 5.6 & 0.0 & 3 & 8.3 & 0.0 & $\mathrm{n} / \mathrm{a}$ & $\mathrm{n} / \mathrm{a}$ & $\mathrm{n} / \mathrm{a}$ \\
\hline Abstinence & 1 & 2.8 & 0.0 & 5 & 13.9 & 0.1 & 1 & 2.8 & 0.0 \\
\hline Other $^{b}$ & 5 & & & 10 & & & 1 & & \\
\hline Total & 145 & & & 162 & & & 152 & & \\
\hline
\end{tabular}

${ }^{a}$ Methods include DMPA and norethindrone enanthate which respondents tended to group together as methods requiring clinic visits

${ }^{\mathrm{b}}$ Other includes with less than 5 responses such as: withdrawal, herbs, calendar method, breastfeeding, oral/anal sex, teas, morning after pill $N$ number, IUD intrauterine device, avg. average, DMPA depot medroxyprogesterone acetate

In Brazil, one informant summarized her perceptions of contraception:

Condom is $100 \%$ safe, protects you against all diseases and pregnancy, it's the perfect method. Pills, sterilization, injections, and IUD only protect against pregnancy, that's a minus. Pills you can always forget to take, injections make you get fat, IUD can make you prone to infections, and sterilization is only for those $100 \%$ confident that they won't have more babies, not for young girls. (Brazil \#27, 20 years old, Gravida 0, taking ART)

Factors in Discontinuing Contraceptives

A total of 261 items were listed with average length of 2.4 items (Table 3). In Kenya, lists averaged 3 items compared to 2 in Brazil and 2.1 in South Africa. There were five main themes: fertility desire of self or partner, no partner/abstinence, side-effects, illness, and interaction with ART.

\section{Fertility Desire}

Desire for a child, seen as "natural" in all sites, independent of HIV status, is a dominant factor in contraceptive discontinuation in Brazil (72.2\%) and Kenya (69.4\%) compared to South Africa (8.3\%). Fertility desire was also highly correlated with parity; $72.0 \%$ of women with no children mentioned fertility desire as a reason for discontinuation compared to $43.4 \%$ of women with one or more children $\left(c^{2}(1, N=108)=6.30\right.$, $p=0.012$ ). Age and ART status did not influence this mention.

She might want to get pregnant because even HIV positive women have the desire to have children. (Kenya \#1048, 40 years old, Gravida 4, Para 4, ARTnaive)

A sub-theme of this topic, fertility desire based on partner's wishes/demands, emerged in Brazil, where 19.4\% mentioned a woman might discontinue contraceptives because of pressure from her partner to have a child, but had low saliency (Smith's $S$ : 0.2). This factor was not mentioned in Kenya or South Africa.

... But usually our man wants a kid with their own blood, even if they will keep cheating on you for the rest of your life, if they do support you and your house, they want one kid or they will leave you. It's like that where I live, doesn't matter if you are positive or not, first you are a sex machine, and later on you are a baby machine. (Brazil \#3, 25 years old, Gravida 4, Para 3, ART-naive)

\section{No Partner}

Lack of a current partner was listed by $36.1 \%$ in Brazil, $11.1 \%$ in Kenya and $0 \%$ in South Africa. Age, parity, and ART status did not impact this mention. However, in South Africa, $83.3 \%$ of respondents listed abstinence as a reason for discontinuation (compared to $36.1 \%$ in Kenya and no mentions in Brazil). Of the 8 women mentioning abstinence as their current method, 7 (87.5\%) were not married. 
Table 3 Listed reasons for contraceptive discontinuation among HIV-positive women in Rio de Janeiro, Brazil; Kericho, Kenya; and Soweto, South Africa $(N=108$, average list length $=2.4$, total items $=261)$

\begin{tabular}{|c|c|c|c|c|c|c|c|c|c|}
\hline \multirow[t]{3}{*}{ Item } & \multicolumn{3}{|c|}{ Brazil } & \multicolumn{3}{|c|}{ Kenya } & \multicolumn{3}{|c|}{ South Africa } \\
\hline & \multicolumn{3}{|c|}{$(N=36$, avg. length $=2.0)$} & \multicolumn{3}{|c|}{$(N=36$, avg. length $=3.0)$} & \multicolumn{3}{|c|}{$(N=36$, avg. length $=2.1)$} \\
\hline & Freq. & $\%$ & Smith's $S$ & Freq. & $\%$ & Smith's $S$ & Freq. & $\%$ & Smith's $S$ \\
\hline Fertility desire & 26 & 72.2 & 0.6 & 25 & 69.4 & 0.5 & 3 & 8.3 & 0.1 \\
\hline Does not have partner & 13 & 36.1 & 0.3 & 4 & 11.1 & 0.1 & $\mathrm{n} / \mathrm{a}$ & $\mathrm{n} / \mathrm{a}$ & $\mathrm{n} / \mathrm{a}$ \\
\hline Partner desire/demands child & 7 & 19.4 & 0.2 & $\mathrm{n} / \mathrm{a}$ & $\mathrm{n} / \mathrm{a}$ & $\mathrm{n} / \mathrm{a}$ & $\mathrm{n} / \mathrm{a}$ & $\mathrm{n} / \mathrm{a}$ & $\mathrm{n} / \mathrm{a}$ \\
\hline Side effects & 2 & 5.6 & 0.0 & 21 & 58.3 & 0.5 & 14 & 38.9 & 0.2 \\
\hline Illness & 2 & 5.6 & 0.0 & 3 & 8.3 & 0.1 & 4 & 11.1 & 0.1 \\
\hline Abstinence & $\mathrm{n} / \mathrm{a}$ & $\mathrm{n} / \mathrm{a}$ & $\mathrm{n} / \mathrm{a}$ & 13 & 36.1 & 0.2 & 30 & 83.3 & 0.8 \\
\hline Interaction with ARVs & $\mathrm{n} / \mathrm{a}$ & $\mathrm{n} / \mathrm{a}$ & $\mathrm{n} / \mathrm{a}$ & 5 & 13.9 & 0.1 & 4 & 11.1 & 0.1 \\
\hline Aging & $\mathrm{n} / \mathrm{a}$ & $\mathrm{n} / \mathrm{a}$ & $\mathrm{n} / \mathrm{a}$ & 4 & 11.1 & 0.1 & 3 & 8.3 & 0.0 \\
\hline To lose weight & $\mathrm{n} / \mathrm{a}$ & $\mathrm{n} / \mathrm{a}$ & $\mathrm{n} / \mathrm{a}$ & $\mathrm{n} / \mathrm{a}$ & $\mathrm{n} / \mathrm{a}$ & $\mathrm{n} / \mathrm{a}$ & 7 & 19.4 & 0.1 \\
\hline Irregular/health bleeding & $\mathrm{n} / \mathrm{a}$ & $\mathrm{n} / \mathrm{a}$ & $\mathrm{n} / \mathrm{a}$ & 5 & 13.9 & 0.1 & $\mathrm{n} / \mathrm{a}$ & $\mathrm{n} / \mathrm{a}$ & $\mathrm{n} / \mathrm{a}$ \\
\hline Other $^{\mathrm{a}}$ & 23 & & & 31 & & & 12 & & \\
\hline Total & 73 & & & 111 & & & 77 & & \\
\hline
\end{tabular}

a Other less than five responses total includes: dislike method, religious principles, "quickies", forget to use method, depression, poor knowledge, HIV+ partner, intoxication, tired of using condoms, etc

$N$ number, avg. average

\section{Side Effects}

In Kenya (58.3\%) and South Africa (38.9\%), side effects were a major factor for discontinuation, compared to Brazil (5.6\%). Neither age nor ART status impacted this mention, independent of site. Both side effects and parity were highly correlated by site. In a sub-analysis by method (condoms vs. pills vs. injectables/implants), listing sideeffects was equally likely across all parity strata. Undesirable side effects included weight gain and menstrual disruption (either increasing "heaviness" or amenorrhea).

Maybe she is on a method which stops menses and yet she is positive and for this case she has to menstruate so that the virus in the body can reduce... (Kenya \#1059, 33 years old, Gravida 4, Para 2, taking ART)

However, in South Africa, weight loss was an undesirable side-effect for $19.4 \%$ of respondents.

[My ideal contraceptive] must cause weight gain because I am losing weight (South Africa \#72, 20 years old, Gravida 3, Para 2, ART-naive).

\section{Interaction with $A R T$}

In Kenya (13.9\%) and South Africa (11.1\%), perceived interaction between contraceptives and ART was a reason for discontinuation, though not in Brazil.
Taking other medication: if I take ARTs and use Depo, I can be ill. (South Africa \#73, 21 years old, Gravida 2, Para 2, ART-naive)

Some respondents suggested that doctors may advise method discontinuation/change based on possible interactions.

Illness

Illness or severe symptomatic side effects (e.g. high blood pressure) were mentioned as discontinuation reasons by a minority of participants (South Africa, 11.1\%; Kenya, 8.3\%; Brazil 5.6\%). Mentioning illness was not linked to age, parity, or ART status.

Factors in Selecting Contraceptives

A total of 273 responses were collected with average list length of 2.5 items (Table 4). Longer lists were produced in Kenya and Brazil compared to South Africa (average items $=2.9$ and 2.8 vs. 1.8). There were 10 emergent themes.

\section{Prevent HIV Re-Infection}

Preventing HIV re-infection was mentioned by $41.7 \%$ of Brazilian participants, compared to $38.9 \%$ in South Africa and $27.8 \%$ in Kenya. Of these women, $40 \%$ reported 
Table 4 Considerations for choosing a contraceptive method by HIV-positive women in Rio de Janeiro, Brazil; Kericho, Kenya; and Soweto, South Africa $(N=108$, average list length $=2.5$, total items $=273)$

\begin{tabular}{|c|c|c|c|c|c|c|c|c|c|}
\hline \multirow[t]{3}{*}{ Item } & \multicolumn{3}{|l|}{ Brazil } & \multicolumn{3}{|c|}{ Kenya } & \multicolumn{3}{|c|}{ South Africa } \\
\hline & \multicolumn{3}{|c|}{$(N=36$, avg. length $=2.8)$} & \multicolumn{3}{|c|}{$(N=36$, avg. length $=2.9)$} & \multicolumn{3}{|c|}{$(N=36$, avg. length $=1.8)$} \\
\hline & Freq. & $\%$ & Smith's $S$ & Freq. & $\%$ & Smith's $S$ & Freq. & $\%$ & Smith's $S$ \\
\hline Prevent re-infection & 15 & 41.7 & 0.2 & 10 & 27.8 & 0.2 & 14 & 38.9 & 0.3 \\
\hline Prevent STIs & 15 & 41.7 & 0.4 & 14 & 38.9 & 0.2 & 1 & 2.8 & 0.0 \\
\hline Prevent Pregnancy & 15 & 41.7 & 0.3 & 8 & 22.2 & 0.1 & 7 & 19.4 & 0.2 \\
\hline Prevent HIV spread to partner & 13 & 36.1 & 0.2 & $\mathrm{n} / \mathrm{a}$ & $\mathrm{n} / \mathrm{a}$ & $\mathrm{n} / \mathrm{a}$ & 11 & 30.6 & 0.3 \\
\hline Maintain own health & 7 & 19.4 & 0.2 & 16 & 44.4 & 0.4 & 5 & 13.9 & 0.1 \\
\hline Partner agreement & 6 & 16.7 & 0.1 & 2 & 5.6 & 0.0 & $\mathrm{n} / \mathrm{a}$ & $\mathrm{n} / \mathrm{a}$ & $\mathrm{n} / \mathrm{a}$ \\
\hline Few side effects & 3 & 8.3 & 0.1 & 11 & 30.6 & 0.2 & 4 & 11.1 & 0.1 \\
\hline Interactions with ART & 3 & 8.3 & 0.0 & 5 & 13.9 & 0.1 & $\mathrm{n} / \mathrm{a}$ & $\mathrm{n} / \mathrm{a}$ & $\mathrm{n} / \mathrm{a}$ \\
\hline Prevent MTCT & 3 & 8.3 & 0.1 & 2 & 5.6 & 0.0 & $\mathrm{n} / \mathrm{a}$ & $\mathrm{n} / \mathrm{a}$ & $\mathrm{n} / \mathrm{a}$ \\
\hline Abstinence & $\mathrm{n} / \mathrm{a}$ & $\mathrm{n} / \mathrm{a}$ & $\mathrm{n} / \mathrm{a}$ & $\mathrm{n} / \mathrm{a}$ & $\mathrm{n} / \mathrm{a}$ & $\mathrm{n} / \mathrm{a}$ & 15 & 41.7 & 0.3 \\
\hline Other $^{\mathrm{a}}$ & 21 & & & 38 & & & 9 & & \\
\hline Total & 101 & & & 106 & & & 66 & & \\
\hline
\end{tabular}

${ }^{a}$ Other (less than 5 responses) includes: type of relationship (casual or committed), effect on libido, reliability, affordability, etc $N$ number, MTCT mother to child transmission, STI sexually transmitted infection, avg. average, ART antiretroviral therapy

condoms as their current method. Though not statistically significant, younger participants did not tend to mention this consideration; there was no effect for parity.

You gotta prevent infections, a big problem for those who are struggling with HIV. So, you cannot rely only on pills, or IUD or anything like that. You gotta use condoms together with whatever you like, so you're sure that you won't end up with a co-infection (Brazil \#21, 40 years old, Gravida 10, Para 2, taking ART)

\section{Prevent STIS}

Ability to prevent STIs and effectiveness in doing so was mentioned by $41.7 \%$ of Brazilian, $38.9 \%$ of Kenyan, and $2.8 \%$ of South African respondents. Neither parity nor age affected this consideration; there was insufficient data to determine impact of ART.

\section{Prevent Pregnancy}

Effectively preventing pregnancy was mentioned by $41.7 \%$ of Brazilian, 22.2\% of Kenyan, and $19.4 \%$ of South African respondents. Choosing a specific method to prevent vertical HIV transmission, a sub-theme emphasizing efficacy of pregnancy prevention, was mentioned by a few Brazilian $(8.3 \%)$ and Kenyan (5.6\%) respondents. Neither parity nor age affected this mention; there was insufficient data to determine impact of ART.

\section{Prevent HIV Transmission to Partner}

Preventing HIV transmission to a partner was mentioned by both Brazilian (36.1\%) and South African (30.6\%), but no Kenyan participants. Of women mentioning this, 23 $(88.5 \%)$ were not currently using any contraceptive method. This consideration was not affected by age, parity, marital status, and ART status. When asked what she considers when thinking about contraceptives, one participant responded:

First of all, you think about your health and think about protecting your partner. I mean, you usually do not think only in birth control, it is more than that. You think about preventing infections as well, that's why I'd rather use male condoms. It protects me against unintended pregnancy, protects my boyfriend from getting HIV and, on the top of that, it protects me from getting any infection that he might have. It's safe, there is no side effect, and seems to me like the perfect choice. (Brazil \#16, 37 years old, Gravida 2, Para 1, taking ART)

\section{Interaction with Own Health}

Impact of contraception (especially hormonal methods) on their own health and HIV progression was mentioned by $44.4 \%$ of Kenyan participants, with fewer mentions in Brazil and South Africa (19.4 and 13.9\%, respectively). The youngest group mentioned this consideration more 
$(12 ; 34.4 \%)$ than the middle $(5 ; 7.6 \%)$ or oldest $(11$; $27.5 \%)$ groups $\left(c^{2}(2, N=108)=5.00, p=0.082\right)$. Parity and ART status did not affect this consideration. Generally, in all sites, menstruation reflected health and was a factor in method selection. In South Africa, it was "unhealthy" and "keeping the HIV inside" to stop menstruation, whereas amenorrhea was "convenient" in Brazil.

There was variation within sites on health consequences of amenorrhea. For example, in Kenya, there was a belief that losing blood was unhealthy for HIV+ women:

Injectable [contraceptives] are good because a woman is not able to get her menses especially for a woman who is HIV positive. She should not lose blood because her hemoglobin might be low. (Kenya \#1048, 40 years old, Gravida 4, Para 4, ART-naive)

This statement is countered by the belief quoted earlier from Kenya that menstrual blood loss reduces viral load. Similar variances in significance of menstruation were noted in Brazil and South Africa.

There were also comments about side effects of hormonal contraceptives. For example, in Kenya, one participant commented that excessive bleeding from a hormonal contraceptive caused both discomfort and strained her relationship with her spouse:

I used to bleed every week. It made me feel very uncomfortable. It's not good especially if you have a partner, he cannot have sex with you when you are bleeding... He will feel deprived of his conjugal rights and it can bring conflict. (Kenya \#1053, 32 years old, Gravida 2, Para 2, ART-naive)

\section{Partner Agreement}

The partner's role in method choice was mentioned by $16.7 \%$ of Brazilian, 5.6\% of Kenyan, and no South African respondents. Age, parity, and ART status were not linked to partner agreement. However, participants from all sites mentioned difficulties using condoms, especially with a husband or committed partner, with either this list or the method-specific disadvantages list. Using condoms for "casual" sex was not as problematic as using condoms "at home." Concern for immediate physical well-being due to a partner's behavior replaced consideration of long-term health effects for some women, which was confined to the Brazil site.

You need to take care of your health, so condoms will be the best one. But you also need to look for your safety, and condoms might be dangerous...Like, if I ask my boyfriend to use a condom, he will beat me, as if I was thinking that he is having affairs and might transmit something to me. He can never find out that I'm positive, or I'm dead. So, I just cannot ask for condoms. If he decides to use it, I thank God. But if he decides to make without it, I just ask him to come out of me, and I tell him that I forgot to take my pills... (Brazil \#33, 30 years old, Gravida 1, Para 1, taking ART)

\section{Side Effects}

Respondents from all sites (Kenya, 30.6\%; South Africa, $11.1 \%$; Brazil, $8.3 \%$ ) mentioned considering various side effects. Age did not impact this mention; however, parous women tended to mention this consideration more frequently $\left(c^{2}(2, N=108)=2.29, p=0.131\right)$. Undesired side effects echoed those for Method Characteristics, particularly body size/shape and menstrual changes, including increasing bleeding or amenorrhea.

\section{Interactions with ART}

Some Kenyan (14.0\%), Brazilian (8.3\%), and South African $(2.8 \%)$ participants mentioned that interactions with ART guided method choice. Age, parity, and ART status were not linked to this consideration. Systemic hormonal methods were specifically mentioned as interfering with ART. It can happen that the ART will not work because of the [hormonal] contraception (South Africa \#74, 18 years old, Gravida 2, Para 2, taking ART).

\section{Abstinence}

This consideration was mentioned only in South Africa $(41.7 \%)$.

Features of the Ideal Contraceptive Method

The resulting lists contained 388 total items with an average length of 3.6 items (Table 5). In all sites, preventing pregnancy, STIs, and HIV re-infection were mentioned. For pregnancy prevention, women in the youngest age group $(19 ; 59.4 \%)$ were more likely to list this feature as compared to the middle $(16 ; 44.4 \%)$ and oldest $(11 ; 27.5 \%)$ groups, $\left(c^{2}(2, N=108)=7.46, p=0.024\right)$. Parity was also a significant factor with $58(69.9 \%)$ women with one or more children listing preventing pregnancy compared to $11(44.0 \%)$ with no children, $\left(c^{2}(1, N=108)=5.58\right.$, $p=0.018)$. Listing preventing HIV re-infection was correlated to being on ART $\left(18 ; 33.3 \%\right.$ vs. $8 ; 17.0 \% ; c^{2}(1$, $N=101)=3.50, p=0.061)$. Only in Brazil did respondents mention the need for the method to be controlled by the woman (34\%), to protect the partner from HIV (20\%), 
Table 5 Qualities of the ideal contraceptive method by HIV-positive women in Rio de Janeiro, Brazil; Kericho, Kenya; and Soweto, South Africa $(N=108$, average list length $=3.6$, total items $=388)$

\begin{tabular}{|c|c|c|c|c|c|c|c|c|c|}
\hline \multirow[t]{3}{*}{ Item } & \multicolumn{3}{|l|}{ Brazil } & \multicolumn{3}{|c|}{ Kenya } & \multicolumn{3}{|c|}{ South Africa } \\
\hline & \multicolumn{3}{|c|}{$(N=36$, avg. length $=3.6)$} & \multicolumn{3}{|c|}{$(N=36$, avg. length $=2.9)$} & \multicolumn{3}{|c|}{$(N=36$, avg. length $=4.4)$} \\
\hline & Freq. & $\%$ & Smith's $S$ & Freq. & $\%$ & Smith's $S$ & Freq. & $\%$ & Smith's $S$ \\
\hline Prevent STIs & 29 & 83.0 & 0.6 & 20 & 56.0 & 0.4 & 9 & 25.0 & 0.1 \\
\hline Prevent pregnancy & 27 & 77.0 & 0.5 & 9 & 25.0 & 0.2 & 12 & 33.0 & 0.2 \\
\hline Prevents re-infection & 15 & 43.0 & 0.2 & 2 & 6.0 & 0.0 & $\mathrm{n} / \mathrm{a}$ & $\mathrm{n} / \mathrm{a}$ & $\mathrm{n} / \mathrm{a}$ \\
\hline Woman controls it & 12 & 34.0 & 0.3 & $\mathrm{n} / \mathrm{a}$ & $\mathrm{n} / \mathrm{a}$ & $\mathrm{n} / \mathrm{a}$ & $\mathrm{n} / \mathrm{a}$ & $\mathrm{n} / \mathrm{a}$ & $\mathrm{n} / \mathrm{a}$ \\
\hline Protects partner from HIV & 7 & 20.0 & 0.1 & $\mathrm{n} / \mathrm{a}$ & $\mathrm{n} / \mathrm{a}$ & $\mathrm{n} / \mathrm{a}$ & $\mathrm{n} / \mathrm{a}$ & $\mathrm{n} / \mathrm{a}$ & $\mathrm{n} / \mathrm{a}$ \\
\hline Undetectable by partner & 5 & 14.0 & 0.1 & $\mathrm{n} / \mathrm{a}$ & $\mathrm{n} / \mathrm{a}$ & $\mathrm{n} / \mathrm{a}$ & 1 & 3.0 & 0.0 \\
\hline Easily accessible & 5 & 14.0 & 0.1 & 3 & 8.0 & 0.1 & 2 & 6.0 & 0.0 \\
\hline Gel you can "smear" on & 4 & 11.0 & 0.1 & $\mathrm{n} / \mathrm{a}$ & $\mathrm{n} / \mathrm{a}$ & $\mathrm{n} / \mathrm{a}$ & 2 & 6.0 & 0.1 \\
\hline Few side effects & 4 & 11.0 & 0.0 & 13 & 36.0 & 0.2 & 12 & 33.0 & 0.2 \\
\hline Used at time of sex & 4 & 11.0 & 0.1 & 1 & 3.0 & 0.0 & 2 & 6.0 & 0.0 \\
\hline Long lasting (>1 week) & 3 & 9.0 & 0.0 & 11 & 31.0 & 0.2 & 18 & 50.0 & 0.3 \\
\hline Reliable & 1 & 3.0 & 0.0 & $\mathrm{n} / \mathrm{a}$ & $\mathrm{n} / \mathrm{a}$ & $\mathrm{n} / \mathrm{a}$ & 4 & 11.0 & 0.1 \\
\hline Condom & 1 & 3.0 & 0.0 & 7 & 19.0 & 0.2 & 4 & 11.0 & 0.1 \\
\hline Maintains periods & $\mathrm{n} / \mathrm{a}$ & $\mathrm{n} / \mathrm{a}$ & $\mathrm{n} / \mathrm{a}$ & 3 & 8.0 & 0.0 & 15 & 42.0 & 0.3 \\
\hline Prevent periods & $\mathrm{n} / \mathrm{a}$ & $\mathrm{n} / \mathrm{a}$ & $\mathrm{n} / \mathrm{a}$ & 10 & 28.0 & 0.2 & 8 & 22.0 & 0.1 \\
\hline Injection & $\mathrm{n} / \mathrm{a}$ & $\mathrm{n} / \mathrm{a}$ & $\mathrm{n} / \mathrm{a}$ & 1 & 3.0 & 0.0 & 8 & 22.0 & 0.2 \\
\hline No weight gain & $\mathrm{n} / \mathrm{a}$ & $\mathrm{n} / \mathrm{a}$ & $\mathrm{n} / \mathrm{a}$ & $\mathrm{n} / \mathrm{a}$ & $\mathrm{n} / \mathrm{a}$ & $\mathrm{n} / \mathrm{a}$ & 7 & 19.0 & 0.1 \\
\hline Prevents HIV spread & $\mathrm{n} / \mathrm{a}$ & $\mathrm{n} / \mathrm{a}$ & $\mathrm{n} / \mathrm{a}$ & $\mathrm{n} / \mathrm{a}$ & $\mathrm{n} / \mathrm{a}$ & $\mathrm{n} / \mathrm{a}$ & 7 & 19.0 & 0.1 \\
\hline Abstinence & $\mathrm{n} / \mathrm{a}$ & $\mathrm{n} / \mathrm{a}$ & $\mathrm{n} / \mathrm{a}$ & $\mathrm{n} / \mathrm{a}$ & $\mathrm{n} / \mathrm{a}$ & $\mathrm{n} / \mathrm{a}$ & 5 & 14.0 & 0.1 \\
\hline Oral & $\mathrm{n} / \mathrm{a}$ & $\mathrm{n} / \mathrm{a}$ & $\mathrm{n} / \mathrm{a}$ & 1 & 3.0 & 0.0 & 4 & 11.0 & 0.1 \\
\hline Other $^{a}$ & 9 & & & 23 & & & 38 & & \\
\hline Total/Average: & 126 & & & 104 & & & 158 & & \\
\hline
\end{tabular}

${ }^{a}$ Other includes: good smell, increase sexual pleasure, an incense, sterilization, etc

$N$ number, STI sexually transmitted infection, avg. average

or to be undetectable by the partner (13.9\%). A womancontrolled method was correlated with ART status, with 8 (14.8\%) on ART mentioning this attribute compared to 1 $(2.1 \%)$ not on $\operatorname{ART}\left(c^{2}(1, N=101)=4.99, p=0.026\right)$. Contraceptives with fewer/no side effects were mentioned by $36 \%$ of Kenyan, $33 \%$ of South African, and $11 \%$ of Brazilian respondents. Duration of action ("long lasting," more than a week) was emphasized by $50 \%$ of South African, $31 \%$ of Kenyan, and $9 \%$ of Brazilian participants. In South Africa, $42 \%$ said the ideal method would maintain menstruation while $22 \%$ listed cessation of menstruation as a required feature. Kenya was reversed with $8 \%$ stating the ideal method would maintain menstruation and $28 \%$ advocating induced amenorrhea. South Africa had several desires that were common only at that site: an injection (22\%), no weight gain (19\%), abstinence (14\%), and an oral contraceptive $(11 \%)$. One respondent summed up the "ideal method" succinctly:

First it has to be something that a woman should be able to use, even if her husband doesn't want to. Like a secret, something that he cannot see, smell, or feel. And it has to be safe, something that doesn't mess up your health. That protects you from getting pregnant and from infections, but does not impede you from having babies later on, not like surgery. I guess that's it, some medicine, some pill that you could take, like, once a month. And once you stop taking it, you will be able to have kids again. (Brazil \#7, 35 years old, Gravida 4, Para 4, taking ART)

\section{Discussion}

This assessment compares the reasons for use and perceived relative merits and drawbacks of contraception among HIV-positive women in three diverse settings. There were multiple commonly held beliefs not altered by age, site, or parity, particularly with respect to fertility desire as a reason to discontinue contraception, advantages and disadvantages of each method, and the specific 
attributes of long duration of action and lack of side-effects for the ideal method. Generally, male condoms were the most frequently utilized method at all sites, among all age and parity groups, and were the preferred method due to dual protection from STIs and pregnancy. However, site did influence perceived challenges in negotiating condom use. This variance was most extreme for Brazilian women, who mentioned the risk of domestic violence resulting from requested condom use, similar to other situations triggering violence in that setting [64]. The stated desire for a woman-controlled method undetectable to the partner may also arise from this aspect of the Brazilian context. We acknowledge that domestic violence occurs and may influence reproductive health choices in South Africa and Kenya, as has been documented in other studies [65-67]. However, even in the IDIs for these two sites, intimate partner violence was rarely mentioned and the chief concern was about partners leaving a relationship due to either revealing HIV serostatus, wanting to use contraception, or insisting upon condom use. In Soweto, the risk of rape was mentioned in both FGDs and IDIs with regard to need for a method that protected a woman from both pregnancy and HIV/STIs that a woman can control. It is possible that Kenyan and South African women felt too inhibited to discuss intimate partner violence in the abbreviated and recorded FLI sessions; however, this may have been a topic of discussion and referral in situations where the interviewer was requested to stop the recorder.

With regard to inconsistent condom use, which appeared to be a concern for women at all sites, emergency contraception (EC) was not mentioned in the FLIs. EC is a valuable agent for preventing unintended pregnancy in scenarios where either a method has not worked appropriately or was not used at the time of coitus. Knowledge of EC among HIV-positive women has been documented to be low in South Africa and is likely low at other sites, suggested by the lack of specific EC mentions and the reported previous unplanned pregnancies among our participants [3]. EC is a valuable modality to both reduce potential unplanned pregnancy and facilitate reproductive health discussions and tailored counseling among HIV care providers, particularly in settings like Kenya and Brazil, where pregnancy termination is highly restricted. Further efforts should be made to expand EC awareness, promotion, and access among both HIV care providers and HIVpositive women, particularly as other preventive medications, such as pre/post-exposure prophylaxis for HIV, for use around the time of coitus are introduced [68].

The predominant listed reason for discontinuing contraception is desired fertility in every site except South Africa. This difference may be related to lower national ART coverage and more recent ART availability, with little resultant change in perceived shorter survival, in
South Africa. In FL probes and both FGDs and IDIs, women in Soweto frequently mentioned concern for leaving orphans [16]. We did not specifically query whether having a previous child who succumbed to AIDS influenced fertility desire or contraceptive use; this experience may additionally shape contraceptive use and deserves future study.

Discontinuation for side-effects, particularly those associated with bleeding and weight changes, was also common to Kenya and South Africa sites and similar to that reported among populations in the United States and Zambia [26, 69]. However, HIV likely factored into intolerance of oligo/amenorrhea and weight loss due to fears of deteriorating health and imminent AIDS, particularly in Kenya and South Africa where ART availability is relatively recent. Similarly, concerns about interactions between hormonal contraceptives and ART were listed only in these two sites, possibly due to lack of local experience with ART at both patient and provider level. Another possible explanation for side-effects being a predominant reason for discontinuation in South Africa and Kenya is perceived access to care or contraception. In settings where access to care or methods is perceived to be limited, women may rely on peer consensus with regard to either method choice or potential significance of physical changes accompanying method initiation. Numerous statements indicated that contraceptive-induced amenorrhea was perceived to be unhealthy, potentially reflecting lack of counseling on the physiologic changes induced by hormonal contraception or acceptance of conventional wisdom over information from medical providers. Further, in busy care settings, providers may not be able to deliver complete counseling and the care structure does not encourage patients to make inquiries of their providers. Further study is needed to determine awareness of potential side effects at time of method initiation and its impact upon continuation in Kenya and South Africa.

By contrast, Brazilian participants overwhelmingly mentioned desired fertility, either alone or to satisfy the needs of a partner, as a reason for discontinuation. This desire for children potentially reflects confidence in avoiding vertical transmission in the post-ART context of HIV as a chronic condition. However, Brazilian women also had fewer children than participants at other sites, likely increasing desire for childbearing. Not having children was the strongest determinant for fertility desire, irrespective of site. This shift underscores the importance of improved, integrated reproductive health services with HIV care as ART coverage expands to ensure ideal timing of pregnancies to minimize vertical transmission.

For determining method choice, fears of infection with another strain of HIV or an STI were more important factors than concern for getting pregnant; however, 
condom use among those concerned about re-infection did not reflect this priority. We believe previously mentioned issues with partner influence on condom use mitigate this decision. Women in Rio de Janeiro, Brazil were more likely to rank preventing pregnancy as highly as preventing infection/re-infection and were more likely to be using a contraceptive method than women at the other sites. Contraceptive use has been associated with ART and ART optimism in Brazil; this optimism may extend to ARTnaïve women as treatment is perceived to be widely available and accessible [70]. Kenyan women were more likely to be married and to mention concern for sideeffects, interaction with ART, and impact on personal wellbeing. We hypothesize this difference reflected either changes associated with ART use at this site, as Kenyan participants were more likely to be on ART, or the need to maintain health to perform household duties and maintain a marital relationship.

Many women stated the ideal contraceptive method would protect them from pregnancy and STIs, with pregnancy prevention being more important to younger and multiparous participants. Preventing HIV re-infection was more important to those on ART, likely reflective of increased knowledge and concerns about drug resistance. South African and Kenyan women were more likely to mention avoidance of side-effects, particularly menstrual and weight changes. However, a sizeable proportion, particularly older participants, listed amenorrhea as a desirable feature at all sites. HIV status adds another dimension to perceptions about menses, particularly with regard to its symbolism of health, which deserve greater scrutiny to address misconceptions and optimize patient selection for methods associated with menstrual changes.

The FL method successfully obtained information in the words of the respondents, thus data collected were contextual in nature. The consistent list length throughout the exercise indicates little fatigue, strengthening the utility of this methodology. However, this method is limited by lack of consistent probing. For example, multiple participants in South Africa, in response to the statement about what to consider when selecting a method, listed the "AbstinenceBe faithful-Condoms" approach without elaborating on whether they personally subscribed to this belief [71]. An additional issue that may have affected the results from South Africa was the change in study personnel for the FL exercise as the skilled interviewer who conducted the FGD and IDIs was not available for this phase of the study. The new staff member was trained and each FLI was assessed with ongoing training to provide an iterative process, in efforts to ensure good quality in the interview process. Further, though the protocol envisioned activities at all sites being conducted simultaneously, in practice this did not occur. The South Africa site completed all activities before the other sites and their experiences informed activities at the other sites; the Kenya site was the last to complete activities and had a site visit from one of the U.S.-based investigators with a training session on qualitative technique and sharing of experiences and challenges from other sites.

Based on our findings from the FGD and IDI phases of the study, there are several themes from South Africa that may not have received adequate attention in the FLIs. There was little commentary on the role of the partner in the FLIs, compared to Kenya and Brazil. By contrast, in the South Africa FGDs and IDIs, many women indicated that men could not be trusted to use a condom, necessitating use of other methods, and that childbearing was expected to secure a marriage or lasting partnership [16]. Also notable was the lack of mention of injectables and reasons for their relative popularity in the FLIs, where condoms emerged as the preferred method. There was also less commentary on the relative importance of contraceptive effects on menstruation than was elicited in FGDs and IDIs, though this was also true of the other sites.

Though overall list length was similar between sites, list administration had to be culturally modulated. For example, interviews in Brazil were more conversational and similar to semi-structured IDIs, yielding more personalized data quickly. By comparison, though lists in Kenya and South Africa were similar in length to those in Brazil, there was some reservation (Kenya) or tendency to socially desirable response (South Africa) that made probing in a culturally appropriate manner for contextual information more challenging. However, at each site, multiple participants requested cessation of recording so they could discuss very painful issues with the interviewer, which was often their first opportunity to do so. This action reflects a multitude of internal, complex, and often contradictory desires and influences that profoundly affect contraceptive use and risk of unintended pregnancy. Thus, we strongly recommend that HIV care encompass counseling with trained providers able to elicit and address these various concerns in a non-judgmental fashion.

This study has several other limitations. First, participants included only women accessing health care, who might be more knowledgeable about contraception. We further limited the numbers representing various age and parity groups to ensure equal representation by these potentially biasing factors but, in so doing, some themes may be under-represented. Sub-themes also may not be categorized in the appropriate priority order as categorization was done based on list order by investigators, rather than pile sorting by participants. The demographic information collected on each participant was limited and did not provide perspective on educational, employment, or economic status, which are factors also potentially 
impacting contraceptive choice [8, 72]. Last, lists were interviewer-administered, possibly increasing likelihood of socially desirable response; we made efforts to reduce this occurrence with trained female staff and phrasing statements in the third person.

\section{Conclusions}

In summary, many factors influence contraceptive choice and continuation among HIV-positive women, with several considerations unique to HIV. Our findings indicate that, while age, ART and partnership status, culture, and number of living children broadly impact fertility and contraception decisions, ART coverage appears to have the greatest impact and necessitates periodic assessments with ART expansion. Further, desired fertility was the most important reason for discontinuation of contraceptive use and should be sensitively addressed by HIV care providers to optimize timing of pregnancy with regard to ART use. Some specific dynamics warrant further context-specific investigation, such as the impact of HIV and ART status upon use and continuation of methods known to alter the menstrual cycle or weight.

On this note, the variation in tolerance of effects associated with hormonal contraception by site underscores changes needed at individual, community, and structural levels. Individual recommendations are that HIV-positive women need education and encouragement in procuring better access to both ART and contraception for themselves. On a community level, context-specific contraceptive counseling techniques need to be developed, with emphasis on tailoring method to the needs of the individual, and accuracy of information to dispel popular misconceptions about use of highly effective methods for HIVpositive women, particularly with regard to concomitant ART use. Our findings also support continued availability of method choice and consideration of listed desired characteristics in method selection. Recommendations for structural changes include political support and funding for both ART and family planning programs and operations research to determine the best model for dual service provision. Generally, contraceptive use was higher in the Brazilian context of greater ART availability and duration and a strong national family planning program, which may serve as one model for other settings. Last, the need for a woman-controlled method with dual protection from HIV/ STI acquisition and pregnancy deserves emphasis and recent promising microbicide development should be closely followed for opportunities to integrate emerging products with current contraceptive methods. To conclude, concerns voiced by many participants are summarized in this statement:
Girl, we don't think about birth control, that's old school, for those boring folks who work with family planning, a pain in the neck, if you ask me. We, women living with HIV, think about prevention as a whole pack. It's not only about preventing unintended pregnancy, you gotta protect your partner from getting HIV, and gotta protect yourself from getting infections or reinfection. (Brazil \#16, 37 years old, Gravida 2, Para 1, taking ART)

Acknowledgments A portion of this study was funded by the Walter Reed Army Institute of Research. The opinions and assertions made by the authors do not reflect the official position or opinion of the U.S. Department of the Navy or Army, or of the respective incountry National HIV/AIDS Control Programs and other Non-Governmental Organizations (NGOs). The authors thank the participants for their time and constructive comments. Financial support was received from the Morris S. Smith Foundation, the Doris Duke Charitable Foundation, the U.S. Military HIV Research Program (Kenya), and from the Special Programme of Research, Development and Research Training in Human Reproduction, World Health Organization (Brazil).

\section{References}

1. Joint United Nations Program on HIV/AIDS (UNAIDS). Report on the Global AIDS Epidemic. Geneva: UNAIDS; 2008.

2. Brogly SB, Watts DH, Ylitalo N, et al. Reproductive health of adolescent girls perinatally infected with HIV. Am J Public Health. 2007;97(6):1047-52.

3. Myer L, Rebe K, Morroni C. Missed opportunities to address reproductive health care needs among HIV-positive women in antiretroviral therapy programmes. Trop Med Int Health. 2007; 12(12):1484-9.

4. Shelton JD, Peterson EA. The imperative for family planning in ART therapy in Africa. Lancet. 2004;364(9449):1916-8.

5. Wilcher R, Cates W. Reproductive choices for women with HIV. Bull World Health Organ. 2009;87(11):833-9.

6. Gillespie D, Bradley H, Woldegiorgis M, Kidanu A, Karklins S. Integrating family planning into Ethiopian voluntary testing and counselling programmes. Bull World Health Organ. 2009;87(11): 866-70.

7. Aglah O, Wohlfahrt D, Farrel BL. Integrating FP into HIV prevention and treatment services: addressing the family planning needs of HIV positive women. Abstract no. WEPE0832. In: AIDS 2006-XVI international AIDS conference, Toronto, Canada. August 16, 2006.

8. Sedgh G, Hussain R, Bankole A, Singh S. Women with an unmet need for contraception in developing countries and their reasons for not using a method. Occasional Report No. 37. New York: Guttmacher Institute; 2007.

9. Morroni C, Myer L, Moss M, Hoffman M. Preferences between injectable contraceptive methods among South African women. Contraception. 2006;73(6):598-601.

10. Debrovner CH, Winikoff B. Trends in postpartum contraceptive choice. Obstet Gynecol. 1984;63(1):65-70.

11. Godecker AL, Thomson E, Bumpass LL. Union status, marital history and female contraceptive sterilization in the United States. Fam Plan Perspect. 2001;33(1):35-41, 49.

12. da Silva MO, Costa MM. Reason, myths and fantasies: preliminary data and reflections about the Portuguese experience 
with LNG-IUS-induced hypomenorrhea. Eur J Contracept Reprod Health Care. 1999;4(1):21-5.

13. Edelman A, Lew R, Cwiak C, Nichols M, Jensen J. Acceptability of contraceptive-induced amenorrhea in a racially diverse group of US women. Contraception. 2007;75(6):450-3.

14. Castle S. Factors influencing young Malians' reluctance to use hormonal contraceptives. Stud Fam Plan. 2003;34(3):186-99.

15. Andia I, Kaida A, Maier M, et al. Highly active antiretroviral therapy and increased use of contraceptives among HIV-positive women during expanding access to antiretroviral therapy in Mbarara, Uganda. Am J Public Health. 2009;99(2):340-7.

16. Laher F, Todd CS, Stibich MA, et al. A qualitative assessment of decisions affecting contraceptive utilization and fertility intentions among HIV-positive women in Soweto, South Africa. AIDS Behav. 2009;13(Suppl 1):47-54.

17. Nattabi B, Li J, Thompson SC, Orach CG, Earnest J. A systematic review of factors influencing fertility desires and intentions among people living with HIV/AIDS: implications for policy and service delivery. AIDS Behav. 2009;13(5):949-68.

18. Maier M, Andia I, Emenyonu N, et al. Antiretroviral therapy is associated with increased fertility desire, but not pregnancy or live birth, among HIV + women in an early HIV treatment program in rural Uganda. AIDS Behav. 2009;13(Suppl 1):28-37.

19. Hoffman IF, Martinson FE, Powers KA, et al. The year-long effect of HIV-positive test results on pregnancy intentions, contraceptive use, and pregnancy incidence among Malawian women. J Acquir Immune Defic Syndr. 2008;47(3):477-83.

20. Taulo F, Berry M, Tsui A, et al. Fertility intentions of HIV-1 infected and uninfected women in Malawi: a longitudinal study. AIDS Behav. 2009;13(Suppl 1):20-7.

21. Cooper D, Moodley J, Zweigenthal V, Bekker LG, Shah I, Myer L. Fertility intentions and reproductive health care needs of people living with HIV in Cape Town, South Africa: implications for integrating reproductive health and HIV care services. AIDS Behav. 2009;13(Suppl 1):38-46.

22. Homsy J, Bunnell R, Moore D, et al. Reproductive intentions and outcomes among women on antiretroviral therapy in rural Uganda: a prospective cohort study. PLoS ONE. 2009;4(1):e4149.

23. Magalhães J, Amaral E, Giraldo PC, Simoes JA. HIV infection in women: impact on contraception. Contraception. 2002;66(2): 87-91.

24. Peltzer K, Chao LW, Dana P. Family planning among HIV positive and negative prevention of mother to child transmission (PMTCT) clients in a resource poor setting in South Africa. AIDS Behav. 2009;13(5):973-9.

25. Mark KE, Meinzen-Derr J, Stephenson R, et al. Contraception among HIV concordant and discordant couples in Zambia: a randomized controlled trial. J Womens Health (Larchmt). 2007; 16(8):1200-10

26. Stringer EM, Kaseba C, Levy J, et al. A randomized trial of the intrauterine contraceptive device vs hormonal contraception in women who are infected with the human immunodeficiency virus. Am J Obstet Gynecol. 2007;197(2):144.e1-8.

27. Borgatti SP. Elicitation techniques for cultural domain analysis. In: Schensul J, LeCompte M, editors. The ethnographer's toolkit, vol. 3. Walnut Creek, CA: Altamira Press; 1999.

28. Quinlan M. Considerations for collecting freelists in the field: examples from ethnobotany. Field Methods. 2005;17(3):219-34.

29. Strauss RP, Sengupta S, Kegeles S, et al. Willingness to volunteer in future preventive HIV vaccine trials: issues and perspectives from three U.S. communities. J Acquir Immune Defic Syndr. 2001;26(1):63-71.

30. Wilk CM, Bolton P. Local perceptions of the mental health effects of the Uganda acquired immunodeficiency syndrome epidemic. J Nerv Ment Dis. 2002;190(6):394-7.
31. Ministério da Saúde-Brasil [MS]. Departamento de Informática do SUS-DATASUS. Informações de saúde. Indicadores de saúde. Indicadores e dados básicos-IBD—2005. Indicadores demográficos. Taxa específica de fecundidade. 2005. http://tab net.datasus.gov.br/cgi/idb2005/a06.htm. Accessed 25 Oct 2010.

32. Ali MM, Cleland J. Sexual and reproductive behaviour among single women aged 15-24 in eight Latin American countries: a comparative analysis. Soc Sci Med. 2005;60(6):1175-85.

33. Ministerio da Saude do Brasil (Brazilian Ministry of Health), Health Surveillance Secretariat, National Programme STD and AIDS. UNGASS: Brazilian Response to the AIDS Epidemic. 2005-2007 Country Progress Report. Brasilia, Brazil: Brazilian Ministry of Health; 2008.

34. Ministerio da Saude do Brasil (Brazilian Ministry of Health)/ CEBRAP). Pesquisa Nacional de Demografia e Saude da Crianca e da Mulher (National Demographic and Health Survey), PNDS 2006. Brasilia: Ministerio da Saude; 2009. http://bvsms.saude. gov.br/bvs/pnds/atividade_sexual.php. Accessed 21 Oct 2010.

35. Segurado AC, Paiva V. Rights of HIV positive people to sexual and reproductive health: parenthood. Reprod Health Matters. 2007;15(29 Suppl):27-45.

36. Paiva V, Santos N, França-Junior I, Filipe E, Ayres JR, Segurado A. Desire to have children: gender and reproductive rights of men and women living with HIV: a challenge to health care in Brazil. AIDS Patient Care STDS. 2007;21(4):268-77.

37. Oliveira F, Kerr L, Frota A, Nóbrega A, Bruno Z, Leitão T, Kendall C, Galvão M. HIV-positive women in northeast Brazil: tubal sterilization, medical recommendation and reproductive rights. AIDS Care. 2007;19(10):1258-65.

38. Santos NJ, Buchalla CM, Fillipe EV, Bugamelli L, Garcia S, Paiva V. Reproduction and sexuality in HIV-positive women, Brazil. Rev Saude Publica. 2002;36(4 Suppl):12-23.

39. Ministerio da Saude do Brasil (Brazilian Ministry of Health)/ CEBRAP). Pesquisa Nacional de Demografia e Saude da Crianca e da Mulher (National Demographic and Health Survey), PNDS 2006. Brasilia: Ministerio da Saude; 2009. http://bvsms.saude. gov.br/bvs/pnds/fecundidade.php. Accessed 21 Oct 2010.

40. Relatório Final da Comissão Nacional sobre Determinantes Sociais da Saúde (CNDSS). As Causas Sociais das Iniquidades em Saude no Brasil. Oswaldo Cruz Foundation, Rio de Janeiro, Brazil. 2008.

41. Minamisava R, Nouer SS, Neto OL, Melo LK, Andrade AL. Spatial clusters of violent deaths in a newly urbanized region of Brazil: highlighting the social disparities. Int $\mathbf{J}$ Health Geogr. 2009;8:66.

42. Sateren WB, Foglia G, Renzullo PO, et al. Epidemiology of HIV1 infection in agricultural plantation residents in Kericho, Kenya: preparation for vaccine feasibility studies. J Acquir Immune Defic Syndr. 2006;43(1):102-6.

43. Foglia G, Sateren WB, Renzullo PO, et al. High prevalence of HIV infection among rural tea plantation residents in Kericho, Kenya. Epidemiol Infect. 2008;136(5):694-702.

44. Kenya National AIDS and STI Control Program (NASCOP), Kenya National AIDS Control Council (NACC), Kenya National Bureau of Statistics (KNBS), National Public Health Laboratory Services (NPHLS), Kenya Medical Research Institute (KEMRI), and the National Coordinating Agency for Population and Development (NCAPD). Kenya AIDS Indicator Survey 2007. Ministry of Public Health \& Sanitation, Republic of Kenya. Nairobi, Kenya. 2009.

45. Kenya Central Bureau of Statistics. Demographic and Health Survey. Nairobi, Kenya: Department of Health; 2003.

46. Analysis, Information Management and Communication Activity (AIM) Project. USAID Country Health Statistical Report: Kenya. USAID, Washington, DC. 2009. 
47. Westoff CF, Cross AR. The stall in the fertility transition in Kenya. In: Paper presented at the international union for the Scientific Study of Population XXV international population conference, Tours, France, July 18-23, 2005.

48. Koome P, Nturibi D, Kichamu G. The effect of declining family planning IEC efforts on contraceptive behaviour: working paper. National Coordinating Agency for Population and Development, Nairobi, Kenya. 2005.

49. Mburugu EK, Adams BN. Families in Kenya. In: Adams BN, Trost J, editors. Handbook of world families. Thousand Oaks, CA: Sage Press; 2005.

50. National Department of Health, South Africa. National HIV and Syphilis Prevalence Survey, South Africa, 2007. Pretoria, South Africa: Department of Health; 2008.

51. Barker PM, Venter F. Setting district-based annual targets for HAART and PMTCT a first step in planning effective intervention for the HIV/AIDS epidemic. SAMJ. 2007;97:916-7.

52. Health Systems Trust. Health Statistics-reproductive health. http://www.hst.org.za/healthstats/ index.php?indtype_id=003006002. Accessed 25 Oct 2010.

53. Buchmann EJ, Mensah K, Pillay P. Legal termination of pregnancy among teenagers and older women in Soweto, 1999-2001. S Afr Med J. 2002;92(9):729-31.

54. Laher F, Lephoto C, Forrest J, Cheyip M, Mohapi L. The impact of parallel HAART and contraception service provision on elective terminations of pregnancy in Soweto, South Africa. In: Abstract \#75. 4th South African AIDS conference. Durban, South Africa; 2009.

55. Mbirimtengerenji ND. Is HIV/AIDS epidemic outcome of poverty in Sub-Saharan Africa? Croat Med J. 2007;48(5):605-17.

56. Vincent L. Virginity testing in South Africa: re-traditioning the postcolony. Cult Health Sex. 2006;8(1):17-30.

57. Nduna M, Farlane L. Women living with HIV in South Africa and their concerns about Fertility. AIDS Behav. 2009; 12(Suppl1):S62-5.

58. Kaida A, Laher F, Money D, Janssen PA, Strathdee SA, Hogg RS, Gray G. Fertility intentions of women of reproductive age in Soweto, South Africa: the influence of expanded access to HAART in an HIV hyper-endemic setting. Am J Public Health, 2010; [Epub ahead of print].

59. Todd CS, Stibich MA, Stanekzai MR, et al. 2006-2007 A qualitative assessment of injection drug use and harm reduction programmes in Kabul, Afghanistan. Int J Drug Policy. 2009; 20(2):111-20.
60. Weller SC, Romney AK. Systematic data collection. Thousand Oaks, CA: Sage Publications; 1988.

61. Bernard HR. Social research methods: qualitative and quantitative approaches. Thousand Oaks, CA: Sage Publications, Inc.; 2000.

62. Borgatti SP. ANTHROPAC 4.0. Natick, MA: Analytic Technologies; 1996.

63. Smith JJ. Using ANTHROPAC 3.5 and a spreadsheet to compute a freelist salience index. Field Methods. 1993;5(3):1-3. http:// fmx.sagepub.com/content/5/3.toc.

64. Schraiber LB, D'Oliveira AF, França Junior I; Grupo de Estudos em População, Sexualidade e Aids. Intimate partner sexual violence among men and women in urban Brazil, 2005. Rev Saude Publica. 2008;42(Suppl 1):127-37.

65. Jewkes R, Dunkle K, Nduna M, Levin J, Jama N, Khuzwayo N, Koss M, Puren A, Duvvury N. Factors associated with HIV serostatus in young rural South African women: connections between intimate partner violence and HIV. Int J Epidemiol. 2006;35(6): 1461-8.

66. Kiarie JN, Farquhar C, Richardson BA, Kabura MN, John FN, Nduati RW, John-Stewart GC. Domestic violence and prevention of mother-to-child transmission of HIV-1. AIDS. 2006;20(13): 1763-9.

67. Alio AP, Daley EM, Nana PN, Duan J, Salihu HM. Intimate partner violence and contraception use among women in SubSaharan Africa. Int J Gynaecol Obstet. 2009;107(1):35-8.

68. Matthews LT, Mukherjee JS. Strategies for harm reduction among HIV-affected couples who want to conceive. AIDS Behav. 2009;13(Suppl 1):5-11.

69. Watts DH, Park JG, Cohn SE, et al. Safety and tolerability of depot medroxyprogesterone acetate among HIV-positive women on antiretroviral therapy: ACTG A5093. Contraception. 2008; 77(2):84-90.

70. Kaida A, Gray G, Bastos FI, et al. The relationship between HAART use and sexual activity among HIV-positive women of reproductive age in Brazil, South Africa, and Uganda. AIDS Care. 2008;20(1):21-5.

71. Harrison A. Hidden love: sexual ideologies and relationship ideals among rural South African adolescents in the context of HIV/AIDS. Cult Health Sex. 2008;10(2):175-89.

72. Piccinino LJ, Mosher WD. Trends in contraceptive use in the United States: 1982-1995. Fam Plan Perspect. 1998;30(1): $4-10,46$ 